\title{
Inhalt.
}

I. Etrufgejetgrud.

Gette

Cinleitenbe Beftimmungen

Criter Teil.

Bon ber Beftrafung ber Berbre⿻上丨, Bergehen und $\mathfrak{u}$ ebertretungen im allgemeinen.

Erfter Ibifnitt. Strafen . . . . . . . 13-42

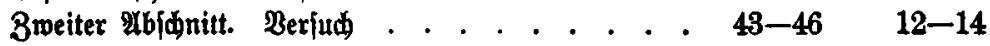

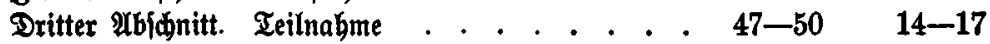

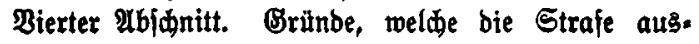

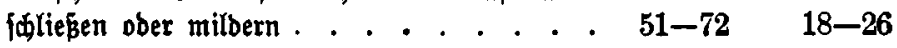

Fünfter Abjønitt. उulammentreffen mebrerer ftraf.

barer Sandlungen . . . . . . . . . 73-79 26-28

\section{3wciter Teil.}

Bon ben einzelnen Berbreden, Bergeben uno

Uebertretungen unb beren $B$ eftrafung.

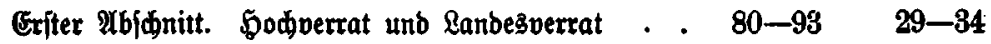

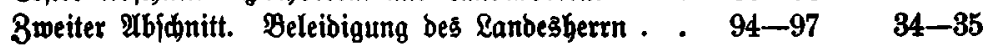

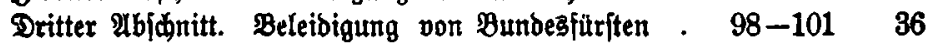

Bierter Ubidnitt. Freindlidbe \$anblungen gegen be.

freunbete Staaten . . . . . . . . . . 102-104 36-37

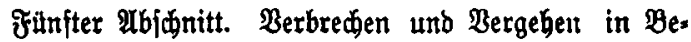

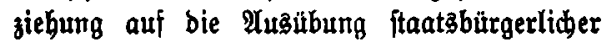

Redte . . . . . . . . . . . . . . 105-109 38-39

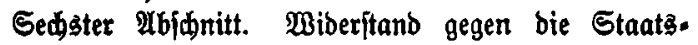

gewalt . . . . . . . . . . . . . . . 110-122 $39-47$

Siebenter abjinnitt. Berbrecten unb Bergeben wiber

bie offentlidje Dronung . . . . . . . . 123-145a 47-58

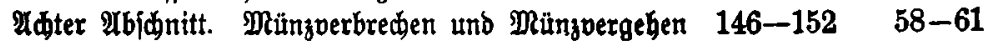

Reunter Abidnitt. Pteineib . . . . . . . . 153-163 61-65 
\$\$ Selte

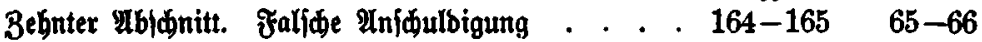
Elfter 2 (bidinitt. Bergeben, welde fith auf bie Meligion beziełen . . . . . . . . . . . . . 166-168 66-68

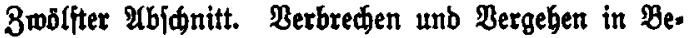
jiebung auf Den Berfonenftand . . . . . . . 169-170 69-70 DreizeGnter $\mathscr{A} b j$ intitt. Berbreden und Bergehen wiber bie Sittlidfleit . . . . . . . . . . .

Bierzebnter $\mathfrak{A}$ bidnitt. Beleibigung . . . . . . Fünfzeb̆nter 21bidnitt. 及weifampf . . . . . . . Sedzehnter $\mathfrak{A b j}$ initt. Berbrechen und $\mathfrak{B}$ bergeben wiber bas Leben. . . . . . . . . . . . . 211-222 $171-184 b \quad 70-81$ $185-200 \quad 81-88$ 201-210 88-90 $211-222 \quad 91-96$ Siebenzebnter Mbjønitt. Sörperverleğung . . . . 223-233 97-104

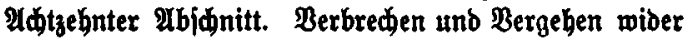

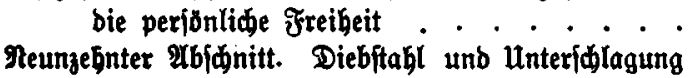
3wanjigfter $\mathfrak{A b i d n i t t . ~ \Re a u b ~ u n d ~ E r p r e f i u n g ~ . ~ . ~ . ~}$

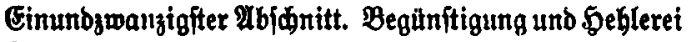

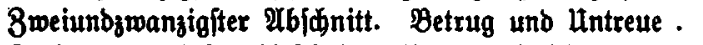

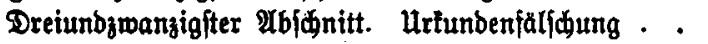

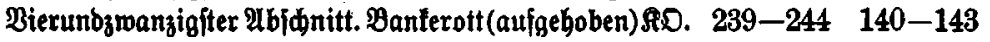

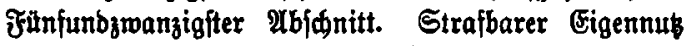
und Berlebung frember Bebeimniffe . . . . 284-302e 143-157

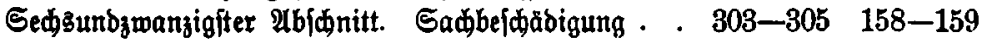
Siebenumbzwanzigfter äbiđnitt. Bemeingefäbrlide Berbreden und Bergehen ........ Qldtunbzwanzigiter Mbidnitt. Berbrtđen und Bergeben in Amte . . . . . . . . . . . . .

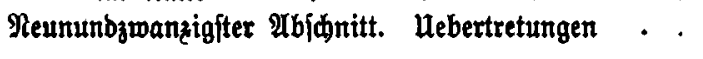
234-241 $104-109$ $242-248 \quad 110-118$ $249-256 \quad 118-122$ $257-262 \quad 122-126$ $263-266$ 126-131 $267-280 \quad 131-140$ $\begin{array}{ll}284-302 e & 143-157 \\ 303-305 & 158-159\end{array}$ $306-330 \quad 160-172$ 331-359 173-186 $360-370 \quad 186-207$

\section{Orubang:}

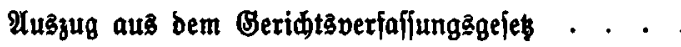
208-214

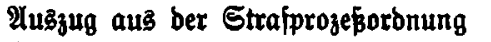
214-227 Saゆregifter 